\title{
SOME OBSERVATIONS ON SWEATING OF THE AINO*
}

\author{
AIKOH KAWAHATA AND HIROSHI SAKAMOTO $\dagger$ \\ Laboratory of Hygiene, College of Medicine, Prefectural University of Mie.
}

It was found by previous investigations that thermal sweat reflex was less prompt in tropic natives $(3,9)$ and that the total number of active sweat glands was largest in tropic natives and Japanese born in the tropics, less in Japanese immigrants to the tropics and those living in Japan proper (4) and much less in Russians settling down in North Manchuria (5). On the other hand, a lot of work has been made on changes in the chloride content of sweat with regard to the function of the sweat glands. Among others it was confirmed that the chlorine concentration was high in the sweat of individuals whose sweat glands were considered to be not in a superior condition and that it was strikingly low in the sweat of tropic natives $(6,7,12)$. The function of the human sweat apparatus seems therefore to be influenced from climatic conditions.

The Ainos are folks domiciliating themselves for successive generations in the province Hokkaido of Japan, the climatic conditions of which are not much different from North Manchuria. With the purpose to add some data to the above problem, thermal sweat reflex, the total number of active sweat glands and the $\mathrm{Cl}$ concentration of sweat were examined on them.

Observations were made in August, 1950, at village of Shiraoi in Hokkaido on 12 Ainos, 2 Japanese born and grown up in Hokkaido and 2 Japanese recently settled. Sweating was induced in a hot room. No special equipment being available, a small ordinary room was used; it was heated by a coal stove and the humidity of the air was kept as high as possible by sprinking water on the floor and walls.

Sweat reflex. In order to testify if there is any difference in the features of sweating between Ainos and Japanese, one each of them was placed together in the room, the temperature of which was kept at about $36^{\circ} \mathrm{C}$. and the courses of their sweatings were observed. A semicirclar filter-paper, $63.8 \mathrm{sq} . \mathrm{cm}$. in dimension, was attached to the outside of upper-arm, covered with a sheet of rubber to prevent evaporation of sweat, and they were fastened together to the arm by a cloth band. The filter-paper was renewed every five minutes and the amount of sweat excreted from the covered skin area was determined by weighing the filter-paper before and after application.

In this way it could be seen how soon sweat breaks out after entering the

Received for publication August 20, 1951.

* The outline of this report was read before the 13th general meeting of Japanese Medical Society.

†川畑愛浩, 坂本 弘 
room and with what rate it further increases. Six experiments were made on 7 Ainos and 3 Japanese. Although the amount of sweat varied considerably in different individuals, no racial difference could be noticed with regard to the latent period and the other general features of sweating.

Chlorine content. As Matsumoto (12) pointed out, chlorine content of sweat should be determined with the sweat produced at maximal sweating as it varies considerably according to the rates of sweating. In the present experiment, the room temperature was kept at $40^{\circ} \mathrm{C}$. or higher and sweat samples were collected after profuse sweating had been continued for more than 20 minutes. Two pieces of filter-paper above mentioned were put on the upper-arm in the same way and left so for 7 to 8 minutes. After determining the amount of sweat by weighing the paper, it was broken into pieces in $5 \mathrm{cc}$. distilled water and $\mathrm{Cl}$ in the water was analysed by Mohr's mothod (13).

The results, expressed as $\mathrm{Cl} \%$, found on 10 Ainos were $0.170,0.191,0.264$, $0.266,0.283,0.285,0.294,0.305,0.359$, and 0.377 respectively (mean 0.279). According to Masui (10), Matsumoto (12) and Kawahata (6), these figures in Japanese ranged from 0.20 to 0.35 . There is therefore no noticeable difference between the two races.

Number of active sweat glands. For investigating sweat droplets Jurgensen's method (2) modified by Kawahata (4) was used. A square figure of $0.084 \mathrm{sq}$. cm. in dimension was previously stamped on the surface of the skin by means of a wooden seal, and the sweat droplets appearing in the area during the maximal sweating were counted. The whole body surface was divided into 20 districts, and the above procedure was made on three to five places in each district. The average of these three to five counts was taken as the average density of active sweat glands over each corresponding district. The total number of sweat glands in each district was computed with reference to its dimension. The number of glands on whole body surface was then calculated by summing up the twenty totals. The extent of each district was measured by the linear formula of $\mathrm{Du}$

Table 1

\begin{tabular}{|c|c|c|}
\hline No. & Age and sex & $\begin{array}{l}\text { Number of sweat glands } \\
\text { (thousands) }\end{array}$ \\
\hline $\begin{aligned} 1 & \text { Aino } \\
2 & \prime \prime \\
3 & \prime \prime \\
4 & \prime \prime \\
5 & \prime \prime \\
6 & \prime \prime \\
7 & \prime \prime \\
8 & \prime \prime \\
9 & \prime \prime \\
10 & \prime \prime \\
11 & \prime \prime \\
12 & \prime \prime\end{aligned}$ & 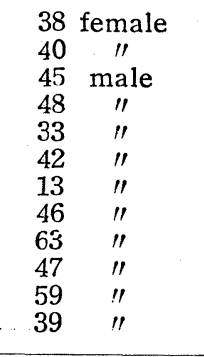 & $\begin{array}{rr}1069 & \\
1180 & \\
1200 & \\
1217 & \\
1336 & \\
1418 & \\
1524 & 1443 \pm 52 \\
1530 & \\
1557 & \\
1564 & \\
1730 & \\
1991\end{array}$ \\
\hline $\begin{array}{l}13 \text { Japanese born } \\
\text { in Hokkaido } \\
14 \text { " }\end{array}$ & $\begin{array}{ll}42 & \prime \prime \\
35 & \prime \prime\end{array}$ & $\begin{array}{ll}1963 & 2098 \pm 91 \\
2233 & \end{array}$ \\
\hline
\end{tabular}


Table 2

\begin{tabular}{|c|c|c|c|c|c|}
\hline & \multirow{2}{*}{$\begin{array}{l}\text { Number of } \\
\text { subjects }\end{array}$} & \multirow{2}{*}{ Age } & \multicolumn{3}{|c|}{$\begin{array}{c}\text { Number of sweat glands } \\
\text { (thousands) }\end{array}$} \\
\hline & & & Min. & Max. & Mean \\
\hline $\begin{array}{l}\text { Russians } \\
\text { Japanese immigrants } \\
\text { Japanese in Japan } \\
\text { Philipinos } \\
\text { Japanese born in tropics }\end{array}$ & $\begin{array}{r}6 \\
4 \\
11 \\
10 \\
15\end{array}$ & $\begin{array}{r}38 \sim 58 \\
14 \sim 35 \\
6 \sim 35 \\
17 \sim 42 \\
9 \sim 25\end{array}$ & $\begin{array}{l}1636 \\
1839 \\
1781 \\
2642 \\
2589\end{array}$ & $\begin{array}{l}2137 \\
2603 \\
2756 \\
2982 \\
4026\end{array}$ & $\begin{array}{l}1886 \pm 59 \\
2168 \pm 11 \\
2282 \pm 66 \\
2800 \pm 23 \\
2961 \pm 61\end{array}$ \\
\hline
\end{tabular}

Bois (1), modified by Kawahata (8).

These observations were of course performed during the maximum state of sweating under similar conditions as above described in the case of measuring chlorine content. The results obtained from 12 Ainos and 2 Japanese born in Hokkaido are summarized in table 1. For reference the results of the previous investigations $(4,5)$ made on Japanese born and grown up in Japan proper, those immigrated to the tropics, those born and grown up in the tropics, tropic natives and Russians are shown in table 2. From table 2 it can clearly be seen that the number of sweat glands is the largest in the tropic natives and Japanese born in the tropics, markedly less in the Japanese residing in Japan or immigrated subsequent to childhood to the tropics and much less in the Russians.

As can be seen from table 1, the number of sweat glands of the Ainos ranges from 1069 to 1991 thousands and is 1443 on an average. These figures are considerably less compared with those found on the Russians who showed the smallest value among the folks so far investigated. It will be noted that the former are less than half those of the tropic natives.

The above result in the Ainos is rather an unexpected one and the question arises if this is due to the effect of climate. The climate in Hokkaido is similar to that of North Manchuria, but the cold is somewhat less severe in the former, in other words, not cold enough as to result in such small numbers of sweat glands in the Aino. It may therefore be assumed that it is partly due to an inherent racial character. No conclusion can, however, be given to this question as the investigations on this line made on natives in cold provinces are so far extremely limited.

\section{SUMMARY}

1. On the Aino thermal sweat reflex, chlorine content of sweat and total number of active sweat glands were observed, and the results were compared with those of the Japanese.

2. No difference could be noticed in the sweat reflex and the chlorine content.

3. The number of sweat glands of 12 Ainos ranged from 1069 to 1991 thousands, i.e. the smallest figures among those so far investigated on other races.

This work was partly aided by a grant from the Ministry of Education. 


\section{REFERENCES}

1. Du BoIs. Arch. Int. Med. 15 : 868, 1915.

2. Juergensen, E. Deutsch. Arch. Klin. Med. 144: 193, 1924.

3. Kawahata, A. J. Mie Med. College. 1: 33, 1950.

4. KAW AhAtA, A. J. Mie Med. College. 1: 25, 1950.

5. Kaw ahatA, A. J. Mie Med. College. 1: 29, 1950.

6. KaW AhatA, A. J. Mie Med. College. 1: 123, 1950.

7. KaWAhat A, A. J. Mie Med. College. 1 : 128, 1950.

8. Kawahat A, A. J. Physiol. Soc. Japan. 5: 246, 1940. J. Mie Med. College. 1: 25, 1950.

9. Kosuge, T. AND A. KAWAhatA. J. Physiol. Soc. Japan. 4: 212, 1939.

10. MASuI, I. J. Physiol. Soc. Japan. 7: 80, 1942.

11. Matsumoto, E. J. Physiol. Soc. Japan. $7:$ 58, 1942.

12. Matsumoto, E. J. Physiol. Soc. Japan. $7: 58,1942$.

13. MOHR, F. Standard methods of chemical analysis. p. 272. (Cited by N. H. Furman.) 